\title{
Revistas culturales y de vanguardia publicadas en España en lengua francesa: una aproximación
}

\author{
Carlota VICENS-PUJOL \\ Universitat de les Illes Balears \\ cvicens@uib.es
}

\section{Resumen}

El objetivo del presente artículo es dar a conocer una selección de periódicos y revistas publicados en francés en España entre 1809 y 1935 . Hoy prácticamente olvidada, esta prensa alófona ofrece un rico testimonio de la época en que fue escrita, pues al tiempo que ilustra sobre el momento histórico y socio-cultural, permite valorar la utilización de la lengua francesa y su impronta en la sociedad española.

Palabras clave: Prensa alófona. Prensa cultural. España. Siglos XIX y XX.

\begin{abstract}
The objective of this article is to present a selection of newspapers and magazines published in French in Spain between 1809 and 1935. Today practically forgotten, this Allophone press offers a rich testimony of the time in which it was written, because while it illustrates The historical and socio-cultural moment allows us to assess the use of the French language and its imprint in Spanish society.
\end{abstract}

Key words: Allophone press. Cultural press. Spain. 19th and 20th Centuries.

\section{Résumé}

L'objectif de cet article est de présenter une sélection de journaux et de magazines publiés en français en Espagne entre 1809 et 1935. Aujourd'hui pratiquement oubliée, cette presse allophone offre un riche témoignage de l'époque à laquelle elle fut écrite. Si elle témoigne du moment historique et socioculturel, elle permet en même temps d'évaluer l'utilisation de la langue française et son empreinte dans la société espagnole.

Mots clé: Presse allophone. Presse culturelle. Espagne. XIX et XX ${ }^{\mathrm{e}}$ siècles.

\footnotetext{
* Artículo recibido el 8/03/2019, aceptado el 25/09/2019.
} 


\section{Introducción}

La subida al trono de la dinastía de los Borbones en España supone el lento declive del español como lengua universal en beneficio del francés, que muy pronto extenderá su hegemonía por toda Europa como también por otros continentes. Ello se mantendrá así hasta la firma del Tratado de Versalles (1919) que, redactado en francés y en inglés, significa "un golpe muy serio para el francés como lengua universal"; a partir de entonces este idioma pasa "de ser la lengua diplomática a ser una lengua diplomática" ${ }^{1}$ (Cantera, 1997: 21). Más allá de las razones políticas existentes, relacionadas sobre todo con la invasión napoleónica, a lo largo de todo el siglo XIX el francés será considerado en Espańa lengua de cultura (o de civilización); su conocimiento supone la apertura de las mentes al espíritu ilustrado y a los grandes principios de la Revolución Francesa, base de todo progreso intelectual y material. Prueba de ello es la Ley General de Instrucción Pública de 1857 (más conocida como Ley Moyano), que introduce el aprendizaje del francés en los "Estudios Generales" (artículo 3), dejando el de otros idiomas para los "Estudios de Aplicación a la Agricultura, el Comercio, las Artes, la Industria".

A principios del siglo XX otro factor nos parece decisivo para explicar el prestigio del francés en España: el esplendor de las vanguardias artísticas. La importante presencia de escritores franceses, traducidos o no, en las revistas españolas de vanguardia y de textos de todo tipo que buscan dar a conocer la nueva estética nacida en el país vecino, mostrando al tiempo su admiración, dan fe del conocimiento de la lengua y la cultura francesas, al menos entre las élites intelectuales españolas. Destaquemos, en estas revistas, las secciones "La novísima literatura francesa. La nueva estética”, de Cervantes; "La moderna poesía francesa”, de Grecia; la "Antología crítica de la novísima lírica francesa", de Vltra o la titulada simplemente, "Antología francesa” de Cosmópolis ${ }^{2}$.

En este contexto histórico-cultural no es de extrañar que en España los siglos XIX y XX conozcan la aparición de una prensa en lengua francesa o bilingüe difícil de catalogar, pues no siempre está digitalizada y parece dispersa en bibliotecas y hemerotecas regionales, a lo que se suma el carácter efímero de muchas de estas publicaciones. Con todo, en estas páginas pretendemos ofrecer una visión panorámica de algunos títulos representativos que vieron la luz en el período comprendido entre la ocupación de la península por las tropas napoleónicas y el comienzo de la Guerra Civil; títulos, señalémoslo, ignorados en el más amplio estudio llevado a cabo hasta ahora sobre el tema (Kraemer, 1995), donde se cita tan solo la revista París-Madrid.

\footnotetext{
${ }^{1}$ El subrayado es nuestro.

${ }^{2}$ Bajo estos epígrafes se ofrecen poemas traducidos de, por ejemplo, Paul Reverdy (Grecia no 2, 1/3/ 1919, p. 5); Max Jacob (Grecia no 8, 1/2/2019, p. 10), Mallarmé (Cosmópolis no2, 1/2/1919, p. 342) o breves reseńas, como la titulada "Antología crítica de la novísima literatura francesa", anónima, sobre la obra poética de Pierre Albert-Birot (Vltra no4, 1/3/1921, p. 4).
} 
El corpus seleccionado comprende un total de seis cabeceras (dos de ellas bilingües) de temática esencialmente cultural: Courrier d'Espagne (1809), L'Exotique. Album de sciences et de littérature (1842), La raza latina (1874), Les matinées espagnoles (1883), 391 (1917) y Biblioteca Fortea. Revista literaria y musical (1935). Todas ellas deben entenderse como curiosidades hemerográficas que, sin embargo, ofrecen un testimonio de la época en su doble vertiente histórico-social y cultural, tal como abordaremos a continuación.

\section{En torno a algunos hechos históricos y la prensa resultante}

Autoproclamado emperador en 1804, Napoleón se lanza a la conquista de Europa y a la organización de un Imperio que, en Espańa, pasa por la designación como rey de José I y el consecuente levantamiento del pueblo español (Guerra de la Independencia, 1808-1814). Con el objetivo de difundir las ideas afrancesadas, un grupo afín ${ }^{3}$ al nuevo monarca lanzó la publicación del Courrier d'Espagne (1809) que, de haber prosperado, habría adquirido el título definitivo de Le courrier espagnol. Sin embargo, no se conoce más que la existencia de un "Prospectus" de dos páginas, lo suficientemente interesante para que le dediquemos unas líneas. El periódico debía salir los martes y jueves a partir del primero de marzo, "en une feuille entière, même papier et caractères que ce prospectus"; el precio previsto era de 100 reales el abono de un año, 55 el de medio año o 30 el de tres meses; para inscribirse los lectores debían dirigirse a la Imprenta francesa (sede de la revista), en la calle Leganitos $n^{\circ} 22$ de Madrid ${ }^{4}$. El nuevo periódico buscaba combatir los prejuicios que envolvían el país (considerado como carente de literatura, de ciencias, de arte en general, de comercio), dar parte de los acontecimientos que sucedían y, sobre todo, poner en valor las letras españolas, a lo que dedica numerosas líneas:

Sur les matières littéraires [...] nous n'en déduirons pas toujours les mêmes conséquences que les critiques français; en rendant compte soit des ouvrages nouveaux, soit de ceux qui publiés depuis longtemps ne sont pas assez connus [...]. Quelque respect que nous ayons pour la littérature française et pour les chefs d'œuvre qui l'ont illustrée, nous ne croirons pas qu'elle soit la seule, qu'il ne puisse y avoir de beau que ce qui est beau en français [...].

\footnotetext{
3 "Fidèles sujets du Roi Joseph Premier, loyaux castillans, dévoués au Prince et à la patrie, nous ne cesserons de servir la cause du premier contre l'aveuglement et l'opiniâtreté [...]" (Courrier d'Espagne, Prospectus, p. 1).

${ }^{4}$ Igualmente podrían abonarse ciudadanos franceses en París, Bayona, Toulouse, Burdeos, Ginebra y Estrasburgo. Estaba previsto que el precio fuera de 36 francos el abono de un año y de 20 el de seis meses.
} 
Un feuilleton sera spécialement consacré à la littérature castillane, et surtout au théâtre, qui a toujours été une de ses branches les plus brillantes.

A Napoleón, sin embargo, le disgustó la aparición de este periódico redactado en francés "por intrigantes" y permitido por lo que consideraba el excesivo liberalismo de José I. En su afán de controlar él mismo la prensa, el emperador escribió al general Clarke, su ministro de guerra, la siguiente nota que debió poner fin a la publicación:

Monsieur le général Clarke, il paraît à Madrid un Courrier d'Espagne rédigé par des intrigants, et qui peut être du plus mauvais effet. Écrivez au maréchal Jourdan pour qu'il n'y ait plus aucun journal français en Espagne et qu'on ait à supprimer celui-là. Mon intention est de ne souffrir, partout où sont mes troupes, aucun journal français, à moins qu'il ne soit publié par mes ordres (Dufour, 2005: 2).

Bajo las órdenes de Napoleón, de sus mariscales o de José I nacieron efectivamente, a lo largo de estos años, numerosos periódicos que se afianzaban a medida que el emperador anexionaba a Francia las regiones del Norte ${ }^{5}$. Algunas de estas cabeceras, que corrieron distinta suerte, o bien eran bilingües o bien contenían textos en francés, como la Gaceta de oficio del Gobierno de Vizcaya, la Gazette de Girone, la Gaceta de Figueras (más tarde titulada Eco de los Pirineos) o la Gazette de Navarre. En esta misma época El Diario de Madrid se militarizó y pasó a ser igualmente bilingüe.

De una contienda bélica nace también La raza latina como reacción frente a la supremacía germánica surgida de la batalla de Sedán (1870), que puso fin a la guerra franco-prusiana. La idea del panlatinismo, sin embargo, coleteaba ya desde Napoleón III, erigido en "defensor de los intereses católicos y protector de los lugares sagrados", es decir, "de la tradición occidental católica [...], idea conservadora y monárquica confirmada por la postura francesa ante la ascensión al poder de Leopoldo O’Donnel en Espańa entre 1854 y 1856" (Torres Martínez, 2016: 17).

Fundado y dirigido por el escritor, periodista y político Juan Valero de Tornos $^{6}$ (1842-1905) el periódico, "internacional y plurilingüe”, se publicó en Madrid entre los ańos 1874 y 1884 , con una periodicidad en principio quincenal. Aunque en la cabecera de los primeros años se indica que se edita en francés, italiano, portugués y espańol, a pesar de los esfuerzos editoriales para lograr colaboraciones provenientes de Italia y Portugal los textos son casi exclusivamente en francés y español. A partir de

\footnotetext{
${ }^{5}$ Seguimos aquí a Checa Godoy (2013), quien habla de hasta treinta títulos que verían la luz entre 1808 y 1814, lo que equivale -afirma- a un 8\% de la prensa española de la época.

${ }^{6}$ Editor también de La Asociación Cientifica, El Porvenir, El Diario del Pueblo o La Suavidad, de corte satírico. Se exilió en París después de la Revolución de 1868, ciudad en la que fundaría y dirigiría El Telégrafo Autógrafo.
} 
septiembre de 1879 , la publicación pasará a subtitularse "revista política, científica y literaria”. El primer número, con fecha 15 de enero de 1874, anuncia ya en su primera plana -escrita en francés ${ }^{7}-$, la finalidad de la revista: "élever [...] un boulevard d'intelligence à la défense de notre race latine, la race qui occupe le poste d'honneur de l'histoire, la première qui a embrassé la foi ; celle qui a la gloire d'avoir servi d'initiatrice à la civilisation moderne". De la lectura del Sumario, detallado en esta primera plana, se desprende ya el carácter y el fin último de la revista. Los artículos que siguen a esta Introducción son los siguientes: "Sur les races" (Antonio Cánovas del Castillo), "La race latine” (Juan López Serrano), "De l'intérêt de l'Italie de s'unir aux races latines" (Jules Favre), "Formation et caractère de la nationalité portugaise" (Juan Alcalá Galiano), "Philosophie du sens comun" (Melitón Martín). Su primer editorial fue el discurso pronunciado por Antonio Cánovas del Castillo, en noviembre de 1870, para acceder a la presidencia del Ateneo de Madrid. Si el discurso debió pronunciarse en castellano, en el periódico aparece en francés en la portada y en español en la segunda página.

De tendencia católica y monárquica, favorable de la restauración borbónica, Valero de Tornos justifica la aparición de la revista como la expresión del deseo de agrupar los países latinos amenazados por Alemania, país que "s'acharne contre le Catholicisme, base inébranlable de notre unión et notre force" ( $\left.\mathrm{n}^{\circ} 3, \mathrm{p} .1\right)$; se trata de, en nombre de los intereses de la raza latina y del catolicismo, "opposer une digue à l'invasion germanique, défendre les croyances sacrées du monde latin, réunir nos efforts et nos interêts au nom du principe catholique" ( $n^{\circ} 3$, p. 1), explica Valero en carta a Jules Favre. Propósito que se va repitiendo y renovando en diferentes números que, invariablemente, muestran su contrariedad por la invasión de protestantes y germanos.

La revista se estructuró en tres secciones: la parte editorial o doctrinal, la literaria y la de colaboraciones, a las que debemos sumar otras de corte menor como la "Revista de política interior", "Movimiento intelectual de la quincena", "La España contemporánea ante el extranjero" o "Revista financiera". No faltan las páginas de literatura, con una "revista teatral" y algunas composiciones en verso.

Entre las firmas francesas destacan las del obispo de Orleans, Félix Dupanloup o del ferviente político republicano Jules Favre, mientras que otras voces más conocidas por el gran público, como las de Victor Hugo, Alexandre Dumas o León Gambetta, son testimoniales. De hecho, en una misiva fechada el 17 de diciembre de 1873, recogida por la misma revista en su número 3, de 15 de febrero de 1874 , Victor Hugo acusa recibo de la invitación a participar en la revista, educadamente y sin comprometerse a ello en ningún momento:

Monsieur,

Je vous envoie tous mes vœux de succès.

${ }^{7}$ Y traducida al español (o viceversa) en la segunda página. 
Puisque vous voulez bien le désirer, je vous ferai participer aux communications que j'ai l'habitude d'adresser à la presse, chaque fois qu'il me semble que notre devoir est d'élever la voix.

Recevez l'assurance de mes sentiments distingués.

Entre los colaboradores españoles destacan Antonio Alcalá Galiano, Gaspar Núñez de Arce, Ramón de Campoamor, Juan Valera o Emilio Castelar; el nombre de Clarín aparece en varias ocasiones como rúbrica a críticas teatrales.

Dirigida a una clase cultivada, la revista, de dieciséis páginas compuestas a dos columnas, prevé distribuirse en Madrid y en otras ciudades y capitales europeas (concretamente en París, Bruselas, Ámsterdam, Roma, Florencia, Lisboa o Londres), además de tener corresponsales en América Latina, Estados Unidos y Filipinas.

\section{Prensa cultural y literaria}

Parece interesante destacar que la prensa en lengua francesa no se cultivaba tan solo en la capital del Reino. Ejemplo de ello es L'Exotique. Album de science et de littérature, periódico semanal fundado en Palma de Mallorca por Jaume Cabanelles: se publicaron un total de 35 números ininterrumpidamente entre el jueves 3 de noviembre de 1842 y el jueves 29 de junio de 1843. Esta cabecera sirve bien no solo como ejemplo de un tipo de prensa del que únicamente se conservan colecciones, sin digitalizar, en bibliotecas regionales, sino también como muestra del prestigio de la lengua francesa entre las élites intelectuales repartidas a lo largo y ancho de la geografía española.

En las islas Baleares el arraigo de la lengua y la cultura francesas se debe en gran medida a la persona de Francesc Jaume Riutort quien, vivamente impresionado por el país vecino después de un viaje a París en 1838, fundó en Palma, en 1842, la Escuela Normal de Enseñanza dirigida a la formación de profesores de instituto, centro en el que se estudiaba francés e italiano ${ }^{8}$. Quizás sea algo más que una simple curiosidad la coincidencia de esta fecha con la de aparición de la revista...

Escritor, periodista y personaje singular, Jaume Cabanelles formó parte de la primera generación de románticos mallorquines y a lo largo de su vida llevó a cabo una intensa tarea cultural en lengua francesa'. Junto al primer número de la revista se publicó un "Prospectus", sin fechar, donde arremete contra el "espíritu comerciante" de la capital balear para concluir diciendo: "Qu'on se rassure [...]. La pensée commerciale n'est pas tellement absorbante dans notre ville qu'elle ne puisse encore s'épancher quelque chose de l'âme sur de plus nobles sujets". Se insiste asimismo en

\footnotetext{
${ }^{8}$ Debemos esta información al Dr. Antoni Marimón.

${ }^{9}$ Además de L'Exotique..., Cabanellas fundó Le Franc Observateur en julio de 1848, del que solo salieron cuatro números. Tres años antes había publicado Le Cicérone français à Palma de Majorque, "guía de viajes" dirigida a los artistas que visitaban la capital balear.
} 
que estas páginas no están dirigidas a una posible colonia francesa instalada en la isla, sino a una juventud instruida: "La langue française, n'est-elle pas le but où vise une jeunesse instruite ? Alors elle secondera de tout son pouvoir notre entreprise".

L'Exotique. Album de science et de littérature no tiene más sección fija que la titulada "Variétés", donde se ponen de manifiesto los acontecimientos culturales destacados de la ciudad. La publicación aborda todos los temas, excepto, como se especifica, los relacionados con la política y la religión, aunque los contenidos son básicamente literarios. Al propio fundador de la revista le debemos muchos de los relatos, poemas o viajes publicados, siendo firmas habituales las de Jules Canonge, Du R., o Dr. Forges. Se insertan igualmente en estas páginas textos (no muchos), casi siempre fragmentados, de reputados escritores franceses; en concreto: "Ange de poésie", de A. Dumas (no 3, 17 noviembre, p. 11-12) y "Le Rhin", de Victor Hugo (no 20, 16 de marzo, p. 77-78), así como una "Notice" sobre Un Hiver à Majorque, de George Sand ( $\mathrm{n}^{\mathrm{o}}$ 15, 9 de febrero, p. 59-60). La revista podía adquirirse en la Imprenta librería de Pierre Joseph Umbert, sita en la Plaza de Cort no 7 y tiene el honor de ser el primer periódico publicado en Mallorca en una lengua extranjera.

El 15 de enero de 1883 veía la luz en Madrid una nueva revista de contenido cultural en francés, Les Matinées espagnoles, impulsada por la condesa María Letizia Rute. El subtítulo de la misma, Nouvelle revue internationale européenne, pasó a ser el título principal a partir del número del 30 de mayo de 1888, inaugurándose así la segunda etapa de una revista que publicaría su último número en $1896^{10}$.

En el banquete inaugural ofrecido a la prensa el 21 de enero, considerado un auténtico "acontecimiento mundano y literario", el barón Stock (pseudónimo de la condesa) justifica la necesidad de esta revista en el panorama periodístico español explicando que la ausencia de periódicos y revistas en francés en España le había llamado la atención más de una vez y que Les Matinées fueron largo tiempo un proyecto “caressé en secret, vingt fois repris, jamais abandonné complètement, jusqu'au jour où je me persuadai que leur apparition comblerait une lacune" (no 1 , sem $1: 100)$.

El banquete se celebró en el domicilio de Mme Rute, c/ Montalbán no 2 de Madrid, que era también la sede de la revista, tal como queda indicado en el pie de imprenta. La impresión ${ }^{11}$ de los números correspondientes al primer semestre se realizó en el Establecimiento Tipográfico de los Sucesores de Rivadeneyra, Madrid, mientras que los números del segundo semestre se imprimieron en la Imprimerie de D.

\footnotetext{
${ }^{10}$ Francisco Lafarga (2013 y 2014) proporciona abundante información al respecto. En estas páginas nos ocuparemos solo de la primera etapa.

${ }^{11}$ Seguimos aquí las consideraciones expuestas por Lafarga (2014).
} 
Joussat y J. Sigaux, París. Posteriormente el pie de imprenta se limita a indicar Madrid-París ${ }^{12}$.

La vocación internacional del semanario (la revista se publica cada domingo, excepto los tres meses de vacaciones, que es quincenal) sale constantemente a relucir. Así, en el número 2 del segundo semestre, se habla de la importancia de dar a conocer los acontecimientos sucedidos en las principales ciudades europeas:

Ne sera-t-il pas intéressant de pouvoir lire dans un même numéro une chronique de Paris ou de Lisbonne, un courrier de Vienne ou de Berlin, un bulletin de Saint-Pétersbourg ou de Florence, une lettre de Rome ou d'Amsterdam, une dépêche de Londres ou de Nice etc etc?

Este mismo número anuncia que la revista será distribuida y tendrá sucursal en Madrid, Lisboa, Roma y París donde el precio del abono será de 30 francos o pesetas seis meses, 40 nueve meses y 50 suponemos que el ańo, aunque no queda especificado. Los nuevos abonados recibirán todos los fascículos ya publicados de Le Cousin Basile y de Le Grand Galeotto. Debido al éxito y a la buena acogida de Les Matinées, estas mismas páginas anuncian la inclusión de nuevas secciones, como la "Semaine europénne", a cargo de M. Andrés Borrego, que recogerá "les faits importants que nous recueillons au jour le jour" y una sección de verano que, bajo el título "Courrier des eaux", dará a conocer los principales centros termales de Europa. Asimismo explica la necesidad de asegurar algunas secciones, en especial "Les Bulletins bibliographiques, les Courriers des beaux-arts, la Revue des théâtres, la Chronique de l'élégance et le Bulletin financier". El contenido se completa con información política, un estudio sobre Herculano, trabajos inéditos de Emilio Castelar y una historia de la Inquisición.

Los números sucesivos parecen dar mayor importancia a la literatura y el arte, por lo que al subtítulo se le añade la coletilla "anecdotique, artistique, politique et littéraire". La condesa, bajo diversos pseudónimos, se erigía en la principal redactora ${ }^{13}$ contando, más en teoría que en la práctica, con la colaboración de importantes escritores contemporáneos. Les Matinées espagnoles pretende asimismo servir de enlace entre las razas latinas, para lo que ofrecerá al lector traducciones de obras destacadas de la literatura española, portuguesa e italiana. Entre los españoles el nombre de Emi-

${ }^{12}$ Con la excepción del volumen correspondiente a los meses de enero-junio de 1884, cuyo pie de imprenta "incluye cuatro menciones: «Madrid (Palais Altamira 18, San Bernardo); Lisbonne (228 rua S. Benito, chez G. Torrezao); París (5, rue Logelbach, Parc Monceau); Rome (chez Bocca)", con la añadidura de la imprenta: Tipografía de Álvarez Hermanos (Madrid)", (Lafarga, 2014: 242).

${ }^{13}$ Los diferentes números encadenan, efectivamente, textos por entregas de la condesa, ya sean originales (la novela Le Huitème péché capital), ya traducciones (Le cousin Basile, Histoire de l'Inquisition). 
lia Pardo Bazán destaca junto al de otros escritores eminentes, cuyas obras aparecen traducidas al francés (con o sin firma de traductor), tales como José Echegaray, Juan Valera o José Antonio de Alarcón. Son igualmente numerosas las reseñas de obras literarias españolas ${ }^{14}$. Al inicio del segundo ańo todo hace pensar a $\mathrm{M}^{\mathrm{a}}$ Letizia Rute que "les Matinées..., fidèles [...] au but qu'elles s'étaient proposé, sont devenues un incontestable trait d'union entre la France, l'Espagne, l'Italie et le Portugal" ${ }^{15}$. Lo que no puede negarse es el esfuerzo hecho en este sentido, pues son escasos los números que no ofrezcan alguna sección bajo el epígrafe "Le Parlement espagnol", "Le Parlement français", "Bulletin de l'Extérieur", "Courrier de Paris", "Courrier de Lisbonne", etc.

Entrado el siglo XX otra revista bilingüe de carácter cultural vería la luz: $B i$ blioteca Fortea. Revista mensual literaria y musical. Publicó un total de 18 entregas entre los ańos 1935 y 1936 e inició una segunda etapa con el título Boletín. Revista de la Biblioteca Fortea que salió entre 1950 y 1951.

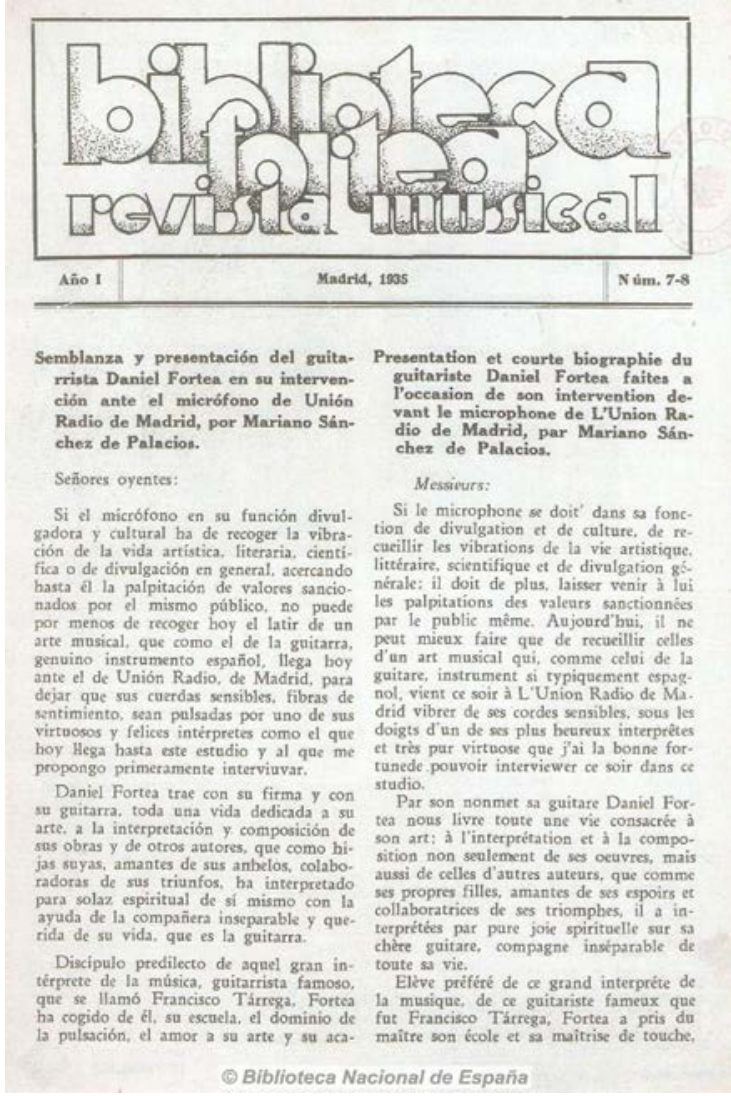

La revista fue publicada y dirigida por Daniel Fortea (18781953), músico español fundador asimismo de la Biblioteca Fortea, de fondos musicales, aún hoy existente. Una semblanza y presentación del director abre el no 7-8 de la revista: se dice de él que "par son nom et sa guitare Daniel Fortea nous a livré toute une vie consacrée à son art ; à l'interprétation et à la composition non seulement de ses oeuvres, mais aussi de celles des autres [...]". Le sigue una entrevista al propio músico, también bilingüe y a doble columna, en la que este se congratula de que su revista ha tenido una muy buena acogida en el extranjero (p. 6). De entre doce y dieciséis páginas, la revista se presenta a dos columnas, en español la de la izquierda y en francés la de la derecha. El porqué de esta decisión se nos escapa, pues no ha sido posible localizar el primer número,

\footnotetext{
${ }^{14}$ Ver la relación de reseñas en Lafarga (2014: 248).

${ }^{15}$ Seconde année - premier semestre - 1er et 7 février $1884-n^{\circ} 2$ et 3 .
} 
donde se establece normalmente la declaración de intenciones. Sin embargo, según las citadas palabras de Fortea, puede obedecerse al deseo de que la revista trascienda la frontera de los Pirineos. La misma Biblioteca Fortea duda de que pueda localizarse este ejemplar, puesto que nunca ha constado en sus propios archivos ${ }^{16}$.

Como se ha dicho, esta revista, bien ilustrada, pretende ser "literaria y musical”, subtítulo que aparece en la segunda página de cada ejemplar. Sin embargo, la cabecera de la página tres indica tan solo "revista musical", y lo cierto es que los artículos de tema literario se reducen a uno, el dedicado al viaje a Espańa de Henri de Régnier, "qui retrace dans un des derniers numéros de la Revue des Deux Mondes un voyage qu'il fit en Espagne, de Barcelone à Majorque" (no 9-10, p.11). Y sin embargo, el comentarista, L. Quievreux, se detiene únicamente en un episodio del viaje en el que Régnier se refiere a música y danzas populares. En ningún momento es cuestión de aspectos literarios ni de la compleja y acaparadora personalidad de Régnier o a sus anteriores viajes a España. De hecho, esta entrega es un monográfico dedicado al músico Francisco Tárrega y en él se halla una alusión al primer número de la revista que, "aparecido poco después del 25 aniversario de la muerte del maestro don Francisco Tárrega", pretendía rendirle homenaje y dedicarle en el futuro un número especial (n 9-10, p. 10). Las secciones fijas son las tituladas: "Noticias", "Biografías" y "Música", mientras que las dos primeras páginas abordan temas más cambiantes en función de la actualidad. Las últimas páginas de cada ejemplar son un catálogo de las obras musicales editadas por Biblioteca Fortea, señalando el precio de cada una de ellas. Centrándonos en cuestiones más prácticas, podemos señalar el precio de la Revista es de 3 pesetas, de 2 en los últimos ejemplares.

\section{Presencia de las vanguardias: la revista 391}

Una de las más curiosas publicaciones en francés editadas en España es sin duda la titulada 391, continuación de 291, revista mensual editada en Nueva York entre marzo de 1915 y marzo de 1916. El artífice de la misma fue Francis Picabia. Procedente de Nueva York, el pintor y poeta llegó a Barcelona en agosto de $1916^{17}$, donde entró en contacto con un pequeño grupo de artistas e intelectuales franceses ${ }^{18}$ que se habían instalado en la ciudad condal una vez comenzada la contienda bélica, entre 1915 y principios de 1916. Fue, sin embargo, su encuentro con el galerista y

\footnotetext{
${ }^{16}$ Según correo electrónico enviado por la actual dirección a requerimiento de la autora de este artículo.

${ }_{17}$ Para estos datos y los sucesivos seguimos en gran medida el estudio hecho por Michel Sanouillet. Ver Bibliografía.

${ }^{18}$ Básicamente el grupo estaba constituido por Francis Picabia y su esposa, Gabrielle Buffet, Albert Gleizes, Maximilien Gauthier, Arthur Cravan, Marie Laurencin y su marido, el marchante alemán Otto von Wätjen, Ricciotto Canudo, Albert Gleizes, Sonia y Robert Delaunay y Serge Charchoune.
} 
gran impulsor de las vanguardias artísticas José Dalmau, quien puso sus oficinas a disposición de Picabia, el hecho definitivo que daría lugar al nacimiento de la revista. Así, en la parte inferior de la contraportada, aparece la siguiente información:

Paraît deux fois par mois. Le numéro : 0,60. Abonnement un an : 12,00. Adresser tout ce qui concerne la Revue, Rédaction et Administration à «391» Galeries Dalmau, Portaferrissa, 18, Téléphone 1791, A. Ce numéro, tiré à 500 exemplaires, dont dix de luxe repris à la main $(10,00)$, a été imprimé par Oliva de Villanova, Casanova 169, Barcelone.

José Dalmau, que aglutinaba en torno suyo el grupo vanguardista llegado básicamente de Francia, hizo coincidir el lanzamiento de 391 con la exposición "Films", del ruso Serge Charchoune. Más allá de la ayuda prestada por Dalmau, Picabia debió tener dificultades para la financiación de la revista, de lo que deja constancia en el primer número: "Evidemment la 391 de Barcelona n'est pas la 291 de New York. Mais où sont MM. Stieglitz, Haviland et de Zayas qui patronnaient la déjà célèbre disparue dont nous reverrons bientôt, n'est-ce pas, les jolies jambes? Pas à Barcelone, assurément" (Picabia, 1915: 4). Así, algo desengañado por una ciudad que consideraba provinciana, no es de extrañar que de los 19 números que vieron la luz entre enero de 1917 y octubre de 1924, solo cuatro (con fechas de 25 de enero, 10 de febrero, 1 de marzo y 25 de marzo) se publicaran en Barcelona ${ }^{19}$. De ellos, los dos primeros ejemplares, de gran tamańo, constan de cuatro páginas; los dos siguientes de ocho. Debido al conflicto bélico, en esta primera etapa de la revista cabe destacar el papel de las mujeres / esposas, de gran importancia para asegurar la calidad artística de la misma:

La frontière espagnole était sévèrement gardée et il eût été imprudent pour des hommes valides de la franchir trop souvent [...]. Les femmes étaient moins vulnérables [...]. Sous le couvert de généreux laissez-passer établis par les soins de $\mathrm{M}$. Roche, elles contribuèrent à maintenir un courant d'échanges qui allait alimenter les rubriques de 391, et sans lequel la revue eût semblablement revêtu une toute autre forme (Sanouillet, 1966: 45)

La portada de cada una de las revistas ofrece un dibujo de Francis Picabia a plena página, titulados respectivamente "Novia", "Peigne", "Flamenca" y "Roulette",

\footnotetext{
${ }^{19}$ El resto, puesto que el pintor abandonó España, vieron la luz en Nueva York (no 5, 6 y 7), Zurich ( $\mathrm{n}^{\circ}$ 8) y París (no 9 a 19). Existe una edición facsímil, que incluye Avant-propos y prólogo a cargo de Michel Sanouillet (1966). Por mi parte, pude acceder a la colección entera en la Biblioteca Jacques Doucet, de París, que sin embargo no me facilitó los derechos de la reproducción parcial de ningún ejemplar. Los números 2 y 3 son accesibles desde el portal Gallica.
} 
mientras que el interior combina dibujos y poesías del mismo Picabia (en ocasiones bajo el pseudónimo de Pharamousse), de Marie Laurencin, Max Goth, Max Jacob o Gabrielle Buffet. A diferencia de las anteriores, esta revista no cuenta con la colaboración de ningún artista español. A modo de ilustración de los contenidos, transcribimos el índice del número 4:

\begin{tabular}{|c|l|l|}
\hline PÁGINA & \multicolumn{1}{|c|}{ TíTULO } & \multicolumn{1}{c|}{ AUTOR } \\
\hline 1 & Roulette (Dibujo) & Picabia \\
\hline 2 & $\begin{array}{l}\text { Bossus (Texto en prosa) } \\
\text { Horreur du vide (Poema) }\end{array}$ & $\begin{array}{l}\text { Picabia } \\
\text { Picabia }\end{array}$ \\
\hline 3 & Musique (Dibujo) & Marie Laurencin \\
\hline 4 & $\begin{array}{l}\text { Romance 1912 (Poema) } \\
\text { Fatigue (Poema) }\end{array}$ & $\begin{array}{l}\text { M. Goth } \\
\text { M. Goth }\end{array}$ \\
\hline 5 & L'Horloge de demain (Poema - dibujo) & G. Apollinaire \\
\hline 6 & $\begin{array}{l}\text { Le Calmant (Poema) } \\
\text { Lion (Poema) }\end{array}$ & $\begin{array}{l}\text { M. Laurencin } \\
\text { M. Laurencin }\end{array}$ \\
\hline 7 & $\begin{array}{l}\text { Évolution (Dibujo) } \\
\text { Petite maison (Poema) }\end{array}$ & $\begin{array}{l}\text { Lloyd } \\
\text { Picabia }\end{array}$ \\
\hline 8 & $\begin{array}{l}\text { Magic City (Poema) } \\
\text { D’une ville infortunée (Texto en prosa) }\end{array}$ & $\begin{array}{l}\text { Picabia } \\
\text { Picabia }\end{array}$ \\
\hline
\end{tabular}

\section{Conclusión}

A principios del siglo XIX la ocupación napoleónica de la Península supuso la creación de una prensa al servicio de los ideales del Imperio, de contenido básicamente político-informativo, que incluía en ocasiones un número variado de artículos en lengua francesa. Por otra parte, a lo largo del siglo XIX y primeras décadas del XX, el francés era considerado en España lengua franca, ejerciendo la cultura francesa una fuerte ascendencia sobre los intelectuales y la burguesía cultivada. En el siglo XIX además, y a pesar de los avatares de la censura, proliferan los suscriptores a todo tipo de periódicos, revistas o folletos al tiempo que se suscita un intenso debate sobre la libertad de prensa (Delgado Idarreta, 2000). A todo ello se suma otro debate, pues el amplio sector de la población y de dirigentes políticos españoles que encontraba en el modelo educativo francés un ejemplo a seguir, chocaba con la oposición de los más conservadores.

Este siglo tan marcado por "lo francés" ve nacer una prensa en lengua francesa de la que ofrecemos aquí una muestra, delimitada a la vez por el tema elegido (prensa cultural), por la dificultad de localizarla y, en menor medida, por los demás artículos de este volumen, que la completan. La visión es pues necesariamente panorámica.

Si el primero de nuestros ejemplos, Le Courrier d'Espagne, no pasó de ser un simple propósito, esta cabecera ilustra bien el férreo control de Napoleón y sus generales sobre la prensa "afrancesada" durante el período 1908-14; de manera más general ejemplifica también la censura que, como se ha indicado, los diferentes gobernan- 
tes ejercían sobre la libertad de prensa y de expresión. Del resto de cabeceras señaladas se desprende que todas ellas, ya naciesen de un acontecimiento histórico preciso o de una clara voluntad cultural, ya fuesen de carácter nacional o de carácter local, obedecen al esfuerzo financiero e intelectual de una sola persona: Valero de Tornos en el caso de La raza latina, Jaume Cabanelles en L'Exotique. Album de sciences et de littérature, Ma Letizia Rute en Les matinées espagnoles, Daniel Fortea en Biblioteca Fortea. Revista literaria y cultural y Francis Picabia en 391. Salvo en esta última, la anunciada colaboración de prestigiosos intelectuales es solo testimonial; además la mayoría de las veces las pretendidas contribuciones, lejos de ser inéditas, son textos que habían sido publicados anteriormente.

Y sin embargo, del elevado número de ejemplares de alguna de estas revistas, como las de Valero de Tornos o Ma Letizia Rute, se desprende un número de lectores / suscriptores nada despreciable. Lectores que tenían un buen manejo de la lengua francesa y que concedían una superioridad manifiesta a la cultura y civilización francesas. En cualquier caso, todas ellas son valioso testimonio de una época en su doble vertiente histórica y socio-cultural.

\section{REFERENCIAS BIBLIOGRÁFICAS}

CANTERA ORTIZ DE URBINA, Jesús (1997): "El francés es y seguirá siendo una lengua universal”, in Arturo Delgado (ed.), Actas del IV Coloquio de la Asociación de Profesores de Filología Francesa de la Universidad Española: Centenario de François Rabelais, Las Palmas de Gran Canaria, Servicio de Publicaciones de la Universidad de Las Palmas de Gran Canaria, 13-26.

CHECA GodoY, Antonio (2013): "La prensa napoleónica en España (1808-1814). Una perspectiva”. El Argonauta español, 10. Disponible en: http://argonauta.revues.org/1848; 22 de noviembre de 2018].

DELGADO IDARRETA, José Miguel (2000): "La prensa: fuente historiográfica”, in J.M. Delgado, ed., Investigación humanistica y cientifica en La Rioja: homenaje a Julio Luis Fernández Sevilla y Mayela Balmasela. Logroño, Instituto de Estudios Riojanos, 245256.

DUFOUR, Gérard (2005): "Une éphémère revue afrancesada : El Imparcial de Pedro Estala (mars-août 1809)”. El Argonauta español, 2. Disponible en: http://journalopenedition.org/argonauta/1193; 30/06/2018).

KRAEMER, Gilles (1995): Trois siècles de presse francophone dans le monde. París, L'Harmattan.

LAFARGA, Francisco (2013): "Teatro francés y teatro en francés en la revista Les matinées espagnoles (1883-1888)”. Anales de Filología Francesa, 21, 123-136.

LAFARGA, Francisco (2014): "Literatura y literatos españoles en la revista Les matinées espagnoles (Madrid-París, 1883-1888)". Anales de literatura española. Literatura y espacio urbano, 26, 239-256. 
SANOUILLET, Michel (1966): Francis Picabia et 391. París, ed. Eric Losfeld.

TORRES MARTíNEZ, Rubén (2016): "Sobre el concepto de América Latina. ¿Invención francesa?". Cahiers d'études romanes 32, 89-98. Disponible en: http://journals.openedition.org/etudesromanes/5141;10/11/2018.

Para citar este artículo / Pour citer cet article :

ViCENS-PujOL, Carlota (2019): «Revistas culturales y de vanguardia publicadas en España en lengua francesa: una aproximación». Çédille, revista de estudios franceses, 16 [Monografías 9: Diana Cooper-Richet, ed., Regards croisés sur la presse francophone en Espagne et la presse hispanophone en France (XVIII ${ }^{e}-X X^{e}$ siècles], 29-42. DOI: https://doi.org/10.25145/j.cedille.2019.17.16.03. 